Original Article

\title{
A PROSPECTIVE STUDY ON RISK FACTORS OF IRON DEFICIENCY ANEMIA IN PREGNANT WOMEN AND THEIR MANAGEMENT
}

\author{
R. DINESH KUMAR ${ }^{1 *}$, M. BOOPATHI RAJA ${ }^{2}$, SREEVEENA P. S. ${ }^{2}$, RACHEL ANN MATHEW ${ }^{2}$ \\ ${ }^{1}$ Department of Pharmacy Practice, the Erode College of Pharmacy, Erode, Tamilnadu, ${ }^{2}$ Doctor of Pharmacy, the Erode College of \\ Pharmacy, Erode, Tamilnadu \\ Email: boopathimurugan11@gmail.com
}

Received: 10 Jul 2020, Revised and Accepted: 08 Sep 2020

\begin{abstract}
Objective: Iron deficiency anemia during pregnancy leads to preterm birth, low birth weight and increases the incidence of postpartum hemorrhage (PPH) and the reason for the incidence of PPH is higher in India compared with the rest of the world. In this study, our main goal was to
\end{abstract} find out the risk factors and complications of iron deficiency anemia and their management in pregnant women.

Methods: It is a prospective study done at Obstetrics and Gynecology Department in Government District Headquarters Hospital, Tiruppur. All subjects were analyzed in full detail and hemoglobin estimation was also done to the patients.

Results: Study found that 52\% shows moderate anemia followed by 30\% mild and 18\% severe, respectively. Risk factors are found in $55 \%$ cases. Study found an association between risk factors and severity of anemia.

Conclusion: Iron deficiency anemia continues to be the commonest etiology of anemia in pregnancy. The prevalence of iron deficiency in a pregnant woman is amongst the highest in the world. Untreated iron deficiency has significant adverse feto-maternal consequences. Iron supplementation and antenatal care are the basic requirements to prevent anemia.

Keywords: Anaemia, Hemoglobin, Risk factors, Pregnancy

(c) 2020 The Authors. Published by Innovare Academic Sciences Pvt Ltd. This is an open access article under the CC BY license (http://creativecommons.org/licenses/by/4.0/) DOI: http://dx.doi.org/10.22159/ijcpr.2020v12i6.40284. Journal homepage: https://innovareacademics.in/journals/index.php/ijcpr

\section{INTRODUCTION}

Iron deficiency and its consequences continue to be prevalent in epidemic proportions despite major health reforms over the past century [1]. Anaemia can be defined by a condition in which the total hemoglobin $(\mathrm{Hb})$ level or the number of red blood cells (RBCs) is poorly lowered. The World Health Organization (WHO) defines anemia as $\mathrm{Hb}<130 \mathrm{~g} / \mathrm{l}$ in men older than $15 \mathrm{y}, 110 \mathrm{~g} / \mathrm{l}$ in pregnant women, and $<120 \mathrm{~g} / \mathrm{l}$ in non-pregnant women older than age $15 \mathrm{y}$ [2]

Iron deficiency anaemia (IDA) is a certain anemic condition arising due to the inadequate iron to form normal RBCs. IDA is usually caused by insufficient iron intake, chronic blood loss, and increased iron demand [3]. Iron is an important dietary mineral associated with many body functions like oxygen transport in the blood. Iron deficiency anaemia is characterized by incomplete hemoglobin synthesis that results in microcytic and hypochromic red blood cells. Due to inadequate hemoglobin, the ability of blood to deliver oxygen to the other body cells and tissues is reduced. Iron deficiency is defined as an imbalance of iron intake, absorption and iron loss. The iron deficiency is the first cause of anemia [4-7].

\section{Causes of IDA in pregnancy women}

Regardless of the various aetiologies, most anaemic patients usually have some component of iron deficiency, which responds to iron administration. With the elderly, the aetiology is attributed to iron deficiency in approximately one-third and chronic renal disease or inflammation accounts to another one-third. The aetiology in the remaining group is often unclear [8]. Latrogenic anaemia or drug induced immune hemolytic anaemia (DIIHA) should be underscored with a growing list of commonly used medications being implicated [9].

\section{Prevalence of IDA in pregnancy}

Globally, the commonest cause for anemia in pregnancy is IDA. The Nutrition Impact Model Study, a systematic analysis of 257 population-representative data sources from 107 countries, estimated the global prevalence of anemia in pregnancy as $43 \%$ in
1995 and 38\% in 2011 with the range varying from 17\% in developed and $56.4 \%$ in developing countries. Etiology of anemia was attributed to ID in $50 \%$ of cases in this study [10]. The prevalence of occult ID in the absence of anemia is estimated to be between 30 and $60 \%$ in pregnant women [11]. In a populationbased study from rural Haryana in 1994-1995, we had found 50\% prevalence of anemia among non-pregnant women in the age group of 16-70 y [12]. Twenty years later, the prevalence of anemia still continues to be $53 \%$ in non-pregnant women and $50 \%$ in pregnant women as per population-based surveys of 2016 in our country [13]. As per the Global Nutrition Report 2016, India ranked miserably at 170 th in terms of anemia prevalence in women [14].

\section{Risk factors of IDA in pregnancy}

Some major risk factors in IDA that includes the following such as having two closely spaced pregnancies and are pregnant with more than one baby, frequently vomiting due to morning sickness, lack of iron consumption in their diet and having a heavy pre-pregnancy menstrual flow with a history of anemia before pregnancy [15].

\section{Complications of IDA in pregnancy}

Anaemia during pregnancy is reported to have negative maternal and child health effects and increase the risk of maternal and perinatal mortality $[16,17]$. The negative health effects for the mother include fatigue, poor work capacity, impaired immune function, increased risk of cardiac diseases, and mortality [16-18]. Some studies have shown that anaemia during pregnancy contributes to $23 \%$ of the indirect causes of maternal deaths in developing countries [18]. Anaemia in pregnancy is associated with increased risk of preterm birth and low birth weight babies [16].

\section{Diagnosing iron deficiency anemia in pregnancy}

Most guidelines recommend screening for anemia during pregnancy in thefirst trimester (or at booking) followed by $24-28 \mathrm{w}$ and at $36 \mathrm{w}$ of gestation [19]. The cut-off values defined by WHO/CDC for anemia in pregnancy along with peripheral smear showing normal 
morphology of RBC with central pallor have often been taken as criteria for fleing the physiologic anemia of pregnancy. A deviation from the above parameters should often be treated as pathologic and warrant further testing for the etiology and appropriate management of anemia during pregnancy [20].

\section{Etiology of IDA in pregnancy}

A history of pre-pregnancy menorrhagia, pre-pregnancy $\mathrm{Hb}$, frequent childbirths, passage of worms and gastrointestinal blood loss should be taken in pregnant patients presenting with anemia. As the etiology of IDA in pregnancy often rfects a mismatch between the supply and demand of iron, we do not recommend stool testing for occult blood, worm infestation, GI endoscopies or screening for celiac disease unless specifically indicated [21].

\section{Treatment for iron deficiency anemia}

\section{Compulsory haemoglobin estimation}

Compulsory Haemoglobin estimation by Cyanmeth-haemoglobin method by using Semi-autoanalyser or photo calorimeter at 14-16 $\mathrm{w}, 20-24 \mathrm{w}, 26-30 \mathrm{w}$ and 30-34 w of pregnancy for all pregnant mothers (minimum four $\mathrm{Hb}$ estimations). The interval between one haemoglobin estimation and another should have a minimum of four weeks.

Table 1: Types of anemia and their level

\begin{tabular}{ll}
\hline HB Level & Classification \\
\hline$<4 \mathrm{~g} / \mathrm{dl}$ & Very severe \\
$4-6.9 \mathrm{~g} / \mathrm{dl}$ & Severe \\
$7-9.9 \mathrm{~g} / \mathrm{dl}$ & Moderate \\
$10-10.9 \mathrm{~g} / \mathrm{dl}$ & Mild \\
\hline
\end{tabular}

\section{Deworming at 14-16th week of gestation (Second trimester)}

All pregnant women at 14-16th week during the second trimester should be given one tablet of Albendazole $400 \mathrm{mg}$-single dose.

\section{At 14-16 w}

First $\mathrm{Hb}$ estimation has to be done at 14-16th week for all the antenatal mothers

- If the $\mathrm{Hb}$ is more than $11 \mathrm{gms} \%$, give prophylactic dose of IFA tablets

- If the $\mathrm{Hb}$ is 7.1-10.9 gms \%, give therapeutic dose of IFA tablets

- If the $\mathrm{Hb}$ is less than $7 \mathrm{gms} \%$, she has to be referred to CEmONC centers for Blood transfusion and further management.

Iron in the form of Ferrous Sulphate is the best choice. Preventive/therapeutic form of oral iron therapy should be started after deworming.

Prophylactic dose: Tab. IFA $(100 \mathrm{mg}$. of iron with $0.5 \mathrm{mg}$ of folic acid) once daily for $100 \mathrm{~d}$.

Therapeutic dosage: Tab. IFA twice daily for $100 \mathrm{~d}$

\section{At 20-24 w}

Second, Haemoglobin estimation has to be done between 20 and 24 $\mathrm{w}$ of gestation for all AN mothers.
- If the $\mathrm{Hb}$ is more than $11 \mathrm{gms}$, give a prophylactic dose of IFA tablets.-

- If the $\mathrm{Hb}$ is $9-10.9 \mathrm{gms} \%$, give therapeutic dose of IFA tablets.

- If haemoglobin level is between 7.1 to $8.9 \mathrm{gm} / \mathrm{dl}$. IV Iron sucrose infusion has to be given.

Intravenous infusion of Iron sucrose-100 mg. in $100 \mathrm{ml}$ of Normal saline infused over 20-30 min once a day x $4 \mathrm{~d}$ over a period of $2 \mathrm{w}$ (with 2-4 d of interval between each infusion)

3/4 Discontinue oral iron therapy while IV iron sucrose infusion till next $\mathrm{Hb}$ estimation and decision (after $4 \mathrm{w}$ of Iron sucrose infusion). Vitamin supplementation need not be withheld.

- If the $\mathrm{Hb}$ is less than $7 \mathrm{gms} \%$, she has to be referred to CEmONC centres for Blood transfusion and further management.

\section{Oral iron therapy}

Practically all medicinal iron preparations contain ferrous compounds. Ferrous fumarate, gluconate and sulfate are commonly used. Other ferrous compounds previously or still in use include ferrous succinate, lactate, glycine sulfate, glutamate, citrate, tartrate and pyrophosphate. Although ferrous succinate is probably more completely absorbed, these compounds, in addition to being more expensive, offer no advantages over ferrous fumarate, gluconate or sulfate. Iron deficiency anaemia Iron tablets contain a percentage of elemental iron that varies with the molecular weight of the iron compounds [22].

Table 2: List of oral ferrous compounds

\begin{tabular}{llll}
\hline Preparation & Iron compound (mg) per tablet & Elemental iron(mg) per tablet & \% of Iron \\
\hline Ferrous fumarate & 200 & 66 & 33 \\
Ferro-us gluconate & 300 & 36 & 12 \\
Ferrous sulfate & 300 & 60 & 20 \\
Ferrous sulfate, anhydrous & 200 & 74 & 37 \\
Ferrous sulfate, exsiccated & 200 & 60 & 30 \\
\hline
\end{tabular}

\section{Parenteral iron therapy \\ Intramuscular (IM) iron}

The Ministry of Health and Family Welfare (MoHFW) guidelines for the treatment of IDA in pregnancy continue to recommend IM iron following a test dose as a cost-effective treatment for moderate anemia in pregnancy [23]. However, the intramuscular route has essentially been replaced by intravenous route because of the inconvenience of painful injection, dark discoloration of the skin, and the risk of myalgias, arthritis, hypersensitivity, lymphadenopathy at most centers [24]. Moreover, there is increased risk of development of sarcoma at the site of injection in treated animals [25]. Low molecular weight iron dextran is the only preparation which can be recommended for intramuscular use in primary care settings with a $\mathrm{Z}$ technique if resuscitation facilities are available [23].

\section{Intravenous iron}

Intravenous (IV) iron combines the advantages of complete bioavailability with fewer GI side effects and faster recovery of $\mathrm{Hb}$ than oral iron. However, the increased risk of oxidant damage, increased cost and small buffinite risk of hypersensitivity reaction 
limit the widespread use of IV iron [26]. The odds ratio/overall risk (OR) of reported total absolute rates of life-threatening adverse events with parenteral iron is 38 per million doses, predominantly with high molecular weight iron dextran [27]. Thus, while the use of high-molecular iron dextran is no longer justified, numerous other iron preparations have been proven to be safe in pregnancy. One of the previous disadvantages of IV iron was the requirement of multiple infusions. This has been circumvented by the newer preparations like iron-isomaltoside and iron carboxymaltose which allow larger infusion doses of elemental iron to be administered over a short period of time $[28,29]$.

\section{MATERIALS AND METHODS}

This prospective study was done among 100 pregnant women who were found to be anemic visited at Department of Obstetrics and Gynecology in Government District Headquarters Hospital,
Tiruppur. Data collection was done after ethical permission from the institutional ethical committee and informed consent of clients.

All subjects were analyzed in full details and hemoglobin estimation done during $1^{\text {st }}$ visit, at $30^{\text {th }}$ week and $36^{\text {th }}$ week of gestation. Blood cultures were done in all the babies admitted to NICU for various reasons. Pre-tested questionnaire was administered and details like socio demographic information, past history of medical illness, menstrual history was collected

\section{RESULTS}

Socioeconomic status of the study participants was analysed. Considering the age group, anemia was found more between 20 to 24 y of age. About $80 \%$ observed in lower socio-economic status. Multi gravida was observed in about $68 \%$ of patients and $58 \%$ of patients were pregnant with less than $2 \mathrm{y}$ of previous pregnancy. Risk factors are found in $55 \%$ of cases.

Table 3: Clinico-social information of study participants $(\mathrm{N}=100)$

\begin{tabular}{|c|c|}
\hline Variable & Numbers (\%) \\
\hline \multicolumn{2}{|l|}{ Age (in year) } \\
\hline$<19$ & 12 \\
\hline $20-24$ & 46 \\
\hline $25-29$ & 22 \\
\hline$>30$ & 20 \\
\hline \multicolumn{2}{|l|}{ Socio-economic status } \\
\hline Lower & 80 \\
\hline Middle & 20 \\
\hline \multicolumn{2}{|l|}{ Literacy status } \\
\hline Illiterate & 25 \\
\hline Primary & 40 \\
\hline Secondary & 20 \\
\hline Graduate & 15 \\
\hline \multicolumn{2}{|l|}{ Parity } \\
\hline Primigravida & 32 \\
\hline Mutltigravida & 68 \\
\hline Spacing between pregnancy (in year) & $(n=100)$ \\
\hline$<2$ & 58 \\
\hline$>2$ & 42 \\
\hline \multicolumn{2}{|l|}{ Risk factor } \\
\hline Present & 55 \\
\hline Absent & 45 \\
\hline \multicolumn{2}{|l|}{ Degree of anaemia } \\
\hline Mild & 30 \\
\hline Moderate & 52 \\
\hline Severe & 18 \\
\hline \multicolumn{2}{|l|}{ Mode of delivery } \\
\hline Vaginal & 65 \\
\hline LSCS & 35 \\
\hline
\end{tabular}

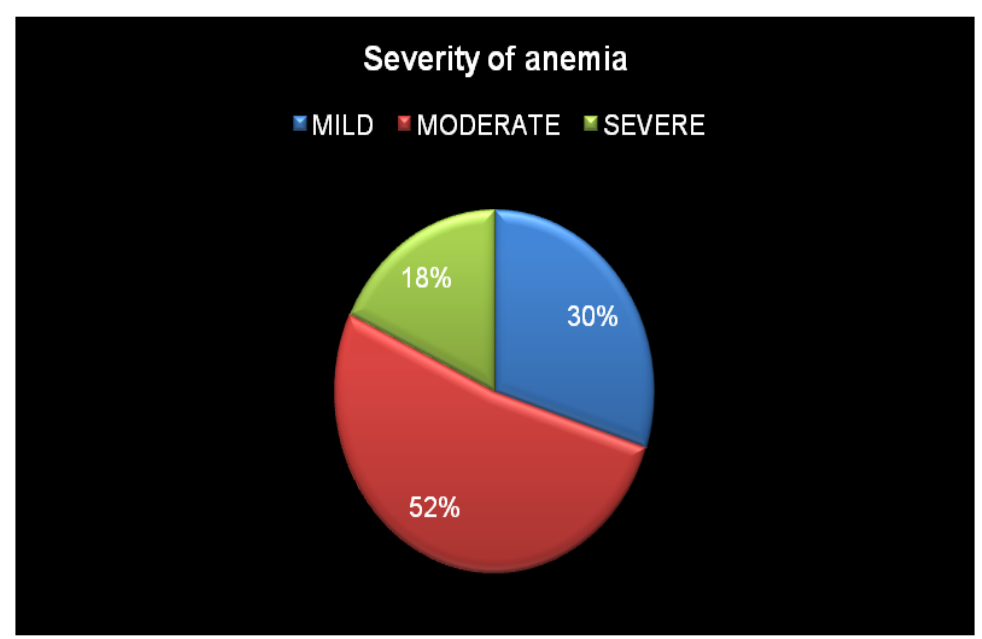

Fig. 1: Shows degree of anemia in patients.18\% shows severe anaemia, $52 \%$ moderate anemia and $30 \%$ showing mild anemia 
Table 4: Association of socio clinical characteristics with severity of Anemia

\begin{tabular}{|c|c|c|c|}
\hline \multicolumn{4}{|c|}{ Variable severity of anaemia } \\
\hline & Mild & Moderate & Severe \\
\hline \multicolumn{4}{|l|}{ Age } \\
\hline$<19$ & 5 & 4 & 2 \\
\hline $20-24$ & 17 & 25 & 6 \\
\hline $25-29$ & 5 & 20 & 8 \\
\hline$>30$ & 1 & 6 & 1 \\
\hline \multicolumn{4}{|l|}{ Literacy } \\
\hline Illiterate & 4 & 24 & 11 \\
\hline Primary & 15 & 15 & 3 \\
\hline Secondary & 9 & 9 & 3 \\
\hline Graduate and above & 2 & 3 & 2 \\
\hline \multicolumn{4}{|c|}{ Socio-economic status } \\
\hline Lower & 23 & 43 & 15 \\
\hline Middle & 6 & 9 & 4 \\
\hline \multicolumn{4}{|l|}{ Gravida } \\
\hline Primigravida & 15 & 15 & 4 \\
\hline Multigravida & 15 & 37 & 14 \\
\hline \multicolumn{4}{|l|}{ Mode of delivery } \\
\hline Vaginal & 21 & 41 & 4 \\
\hline LSCS & 9 & 11 & 14 \\
\hline \multicolumn{4}{|l|}{ Risk factor } \\
\hline $\mathrm{PE}$ & 4 & 14 & 13 \\
\hline PROM & 17 & 16 & 10 \\
\hline Rh-ve & 1 & 4 & 2 \\
\hline Hypothyroidism & 2 & 3 & 4 \\
\hline Placenta PRV & 0 & 1 & 4 \\
\hline Abruptio placenta & 1 & 1 & 0 \\
\hline GHTN & 0 & 2 & 1 \\
\hline \multicolumn{4}{|c|}{ Space between pregnancy } \\
\hline$<2$ & 7 & 23 & 11 \\
\hline$>2$ & 17 & 28 & 14 \\
\hline \multicolumn{4}{|l|}{ Birth weight } \\
\hline$<2.5$ & 24 & 42 & 13 \\
\hline$>2.5$ & 5 & 11 & 5 \\
\hline
\end{tabular}

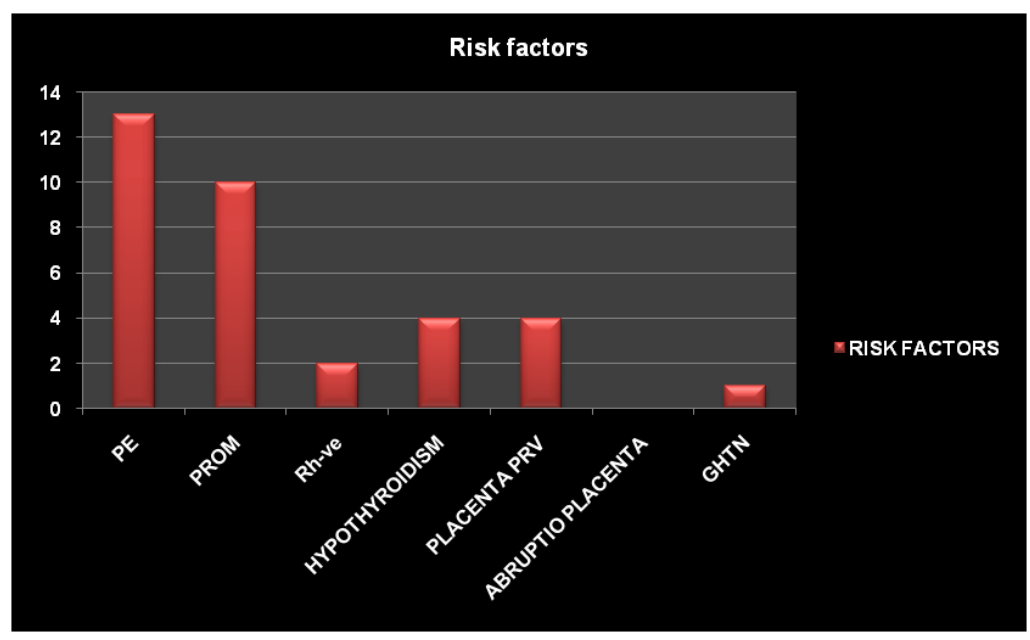

Fig. 2: Shows various risk factors and their association with severe anemia

Table 5: Administration of intravenous iron therapy $(n=30)$

\begin{tabular}{lll}
\hline Drug & Dose & Number of patients \\
\hline Iron sucrose & $100 \mathrm{mg} / 5 \mathrm{ml}$ & 12 \\
Iron carboxymaltose & $500 \mathrm{mg} / 10 \mathrm{ml}$ & 18 \\
\hline
\end{tabular}

Table 6: Administration of oral iron therapy $(n=70)$

\begin{tabular}{lll}
\hline Drug & Dose & No of patients \\
\hline Ferrous sulphate & $200 \mathrm{mg}$ & 24 \\
Ferrous fumarate & $200 \mathrm{mg}$ & 16 \\
Ferrous gluconate & $300 \mathrm{mg}$ & 30 \\
\hline
\end{tabular}




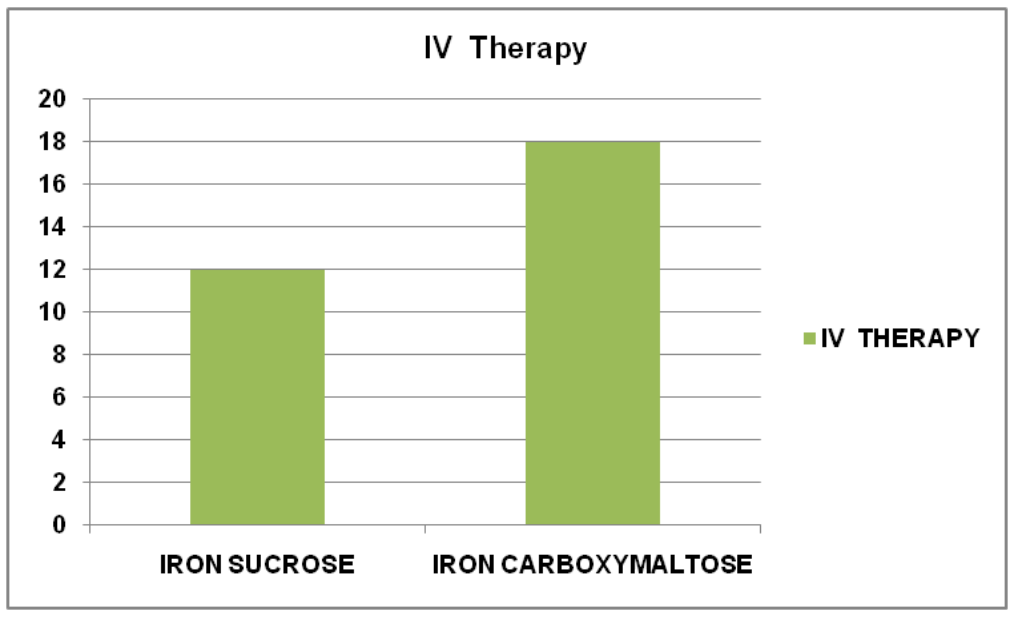

Fig. 3: Administering iron sucrose to 12 patients and iron carboxy maltose to 18 patients

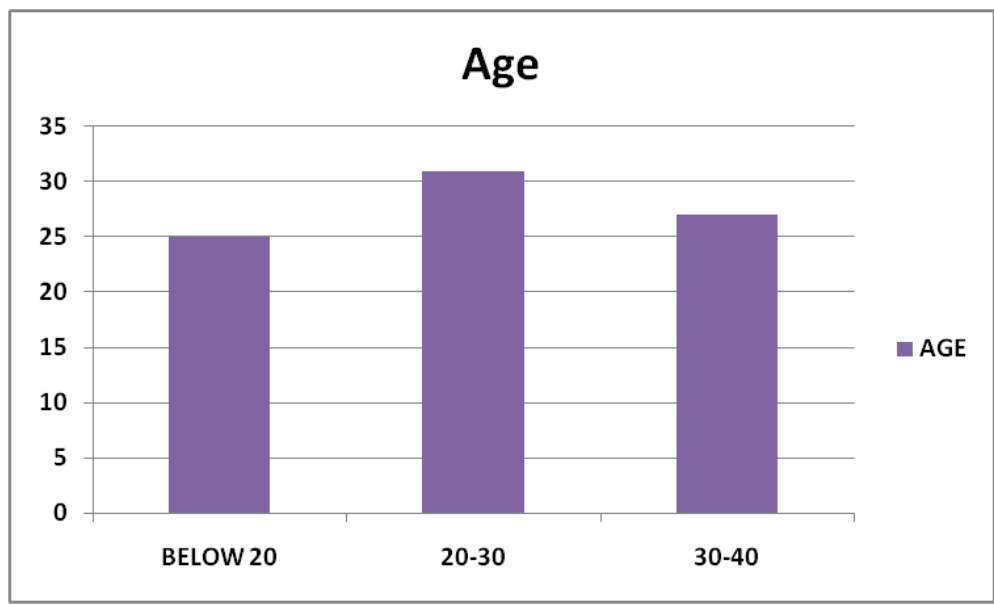

Fig. 4: Administering IV to different age categories

Table 7: Age categorisation of patients

\begin{tabular}{ll}
\hline Age & Number of patients \\
\hline Below 20 & 25 \\
$20-30$ & 31 \\
$30-40$ & 27 \\
Above 40 & 17 \\
\hline
\end{tabular}

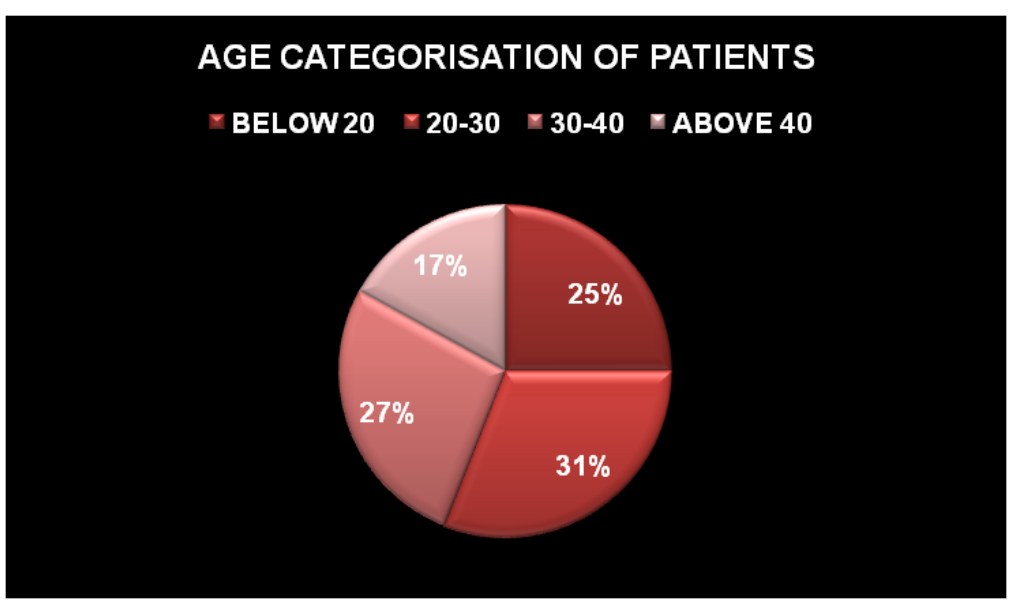

Fig. 5: Different age categorization patients 


\section{DISCUSSION}

Table 1: shows the clinic-social information of study participants. Most participants (46\%) belonged to 20-24 y age group followed by $22 \%$ in $25-29$ y and $12 \%$ in less than 19 y, respectively. Socioeconomic status is divided in two categories. Almost $80 \%$ participants were in lower classes. Around $40 \%$ participants were studied up to primary level followed by illiterate (25\%), secondary level (20\%) and graduation (15\%). Almost 68\% cases were multigravida and $58 \%$ cases pregnant within less than $2 \mathrm{y}$ of previous pregnancy. Present study observe pregnancy related risk factor like PE, PROM, Rh-ve, hypothyroidism, placenta Previa, GHTN, Abruptio placenta. Risk factors present in $55 \%$ cases.

Table 2: shows that severe and moderate anemia seen more among age group of 25 to 29 and 20 to 24 y respectively.

Severe and moderate anemia seen more among illiterate participants and less among literate participants. Anemia is more seen among participants of lower socio-economic class. Multigravida participants are showing more number of moderate and severe anaemia cases than primigravida participants. LSCS observed more among participants with severe anaemia.

Risk factor with severity of anemia was studied and it shows that majority of participants with severe anemia had preeclampsia followed by premature rupture of membrane. Minor risk factor developed in this study is Rh-ve 13 participants with severe anemia and 42 participants with moderate anemia shows low birth weight of less than $2.5 \mathrm{~kg}$.

\section{CONCLUSION}

Iron deficiency anemia continues to be the commonest etiology of anemia in pregnancy. The prevalence of iron deficiency in pregnant woman is amongst the highest in the world. Untreated iron deficiency has significant adverse feto-maternal consequences. Iron supplementation and antenatal care are the basic requirements to prevent anemia.

\section{FUNDING}

Nil

\section{AUTHORS CONTRIBUTIONS}

All the authors have contributed equally.

\section{CONFLICT OF INTERESTS}

\section{Declared none}

\section{REFERENCES}

1. Stevens GA, Finucane MM, De-Regil LM. Global, regional, and national trends in haemoglobin concentration and prevalence of total and severe anaemia in children and pregnant and nonpregnant women for 1995-2011: a systematic analysis of population-representative data. Lancet Glob Health 2013;1:e16-e25.

2. Goddard AF, James MW, McIntyre AS, Scott BB. Guidelines for the management of iron deficiency anaemia. Gut 2011;60:1309-16.

3. WHO. Worldwide prevalence of anaemia 1993-2005. WHO Global Database on Anaemia, Centers for Disease, Control and Prevention, Atlanta; 2008.

4. Akodu OS, Disu EA, Njokanma OF, Kehinde OA. Iron deficiency anaemia among apparently healthy pre-school children in Lagos, Nigeria. Afr Health Sci 2016;16:61-8.

5. Baker SJ, DeMaeyer EM. Nutritional anemia: its understanding and control with special reference to the work of the World Health Organization. Am J Clin Nutr 1979;32:368-417.

6. WHO. Requirements of Vitamin A, Iron, Folate and Vitamin B12: Report of a Joint FAO/WHO expert consultation. FAO/WHO, Rome; 1988. p. 107.
7. Cook JD, Skikne BS, Baynes RD. Iron deficiency: the global perspective. Adv Exp Med Biol 1994;356:219-28.

8. Patel KV. Epidemiology of anemia in older adults. Semin Hematol 2008;45:210-7.

9. Shander A, Javidroozi M, Ashton ME. Drug-induced anemia and other red cell disorders: a guide in the age of polypharmacy. Curr Clin Pharmacol 2011;6:295-303.

10. Stevens GA, Finucane MM, De-Regil LM. Global, regional, and national trends in haemoglobin concentration and prevalence of total and severe anaemia in children and pregnant and nonpregnant women for 1995-2011:a systematic analysis of population-representative data. Lancet Glob Health 2013;1:e16-e25.

11. Daru J, Cooper NA, Khan KS. Systematic review of randomized trials of the effect of iron supplementation on iron stores and oxygen-carrying capacity in pregnancy. Acta Obstet Gynecol Scand 2016;95:270-9.

12. Malhotra P, Kumari S, Kumar R. Prevalence of anemia in adult rural population of North India. J Assoc Phys India 2004;52:1820.

13. Ministry of Health and Family Welfare (2015-2016) Govt. of India, National Family Health Survey (NFHS-4), State Fact Sheet. Mumbai: International Institute for Population Sciences; 2011.

14. Haddad L, Hawkes C, Udomkesmalee E. Global Nutrition Report 2016: From Promise to Impact: Ending Malnutrition by 2030. Washington: International Food Policy Research Institute; 2016.

15. https://www.mayoclinic.org/healthy-lifestyle/pregnancyweek-by-week/in-depth/anemia-during-pregnancy/art20114455 [Last accessed on 05 Jun 2020]

16. LH Allen. Anemia and iron deficiency: effects on pregnancy out come. Am J Clin Nutr 2000;71:1280s-4s.

17. MA Mbule, YB Byaruhanga, $M$ Kabahenda, A Lubowa. Determinants of anaemia among pregnant women in rural Uganda. Rural Remote Health 2013;13:2259.

18. RE Black, CG Victora, SP Walkeretal. Maternalandchild undernutrition and overweight in low-income and middle income countries. Lancet 2013;382:427-51.

19. McDonagh M, Cantor A, Bougatsos C. U. S. preventive services task force evidence syntheses, formerly systematic evidence reviews. routine iron supplementation and screening for iron deficiency anemia in pregnant women: a systematic review to update the US preventive services task force recommendation. Agency for Healthcare Research and Quality (US), Rockville; 2015.

20. Sharma JB, Shankar M. Anaemia in pregnancy. J Int Med Sci Acad 2010;23:253-60.

21. Hershko C, Camaschella C. How I treat unexplained refractory iron deficiency anemia. Blood 2014;123:326-33.

22. Blaud P. Sur les maladies chlorotiques, et sur un mode de traitement spkcifique dans ces affections. [Concerning the chloroses and a specific method of treating these conditions.] Revue m6dicale frangaise et Ptrangande; 1832. p. 45341-367.

23. Achebe MM, Gafter Gvili A. How I treat anemia in pregnancy: iron, cobalamin, and folate. Blood 2017;129:940-9.

24. Silverstein SB, Rodgers GM. Parenteral iron therapy options. Am J Hematol 2004;76:74-8.

25. Camaschella C. Iron deficienc y: new insights into diagnosis and treatment. Hematol Am Soc Hematol Educ Program 2015;2015:8-13.

26. Aronoff GR. Safety of intravenous iron in clinical practice: implications for anemia management protocols. J Am Soc Nephrol JASN 2004;15(Suppl 2):S99-S106.

27. Chertow GM, Mason PD, Vaage Nilsen 0. Update on adverse drug events associated with parenteral iron. Nephrol Dial Transplant 2006;21:378-82.

28. Achebe MM, Gafter Gvili A. How I treat anemia in pregnancy: iron, cobalamin, and folate. Blood 2017;129:940-9.

29. Atkinson LS, Baxley EG. Postpartum fatigue. Am Fam Physician 1994;50:113-8. 